\title{
Treatment interruption of biological drugs and tofacitinib in rheumatoid arthritis: A systematic review of case reports
}

\author{
Astrid Wiens', Helena Hiemisch Lobo Borba ${ }^{1}$, Letícia Paula Leonart ${ }^{1}$, Fernanda Stumpf Tonin ${ }^{1}$, \\ Laiza Maria Steimbach¹, Ariane Gonçalves Silva de Araújoㅁ, Thais Piazza², Vinicius Lins Ferreira ${ }^{1}$, \\ Roberto Pontarolo ${ }^{1}$
}

\author{
${ }^{1}$ Departamento de Farmácia, Universidade Federal do Paraná, Curitiba, Brazil, ${ }^{2}$ Departamento de Farmácia e Administração \\ Farmacêutica, Universidade Federal Fluminense, Rio de Janeiro, Brazil
}

\begin{abstract}
The aim of this study was to evaluate interruption of treatment with biological drugs and tofacitinib due to adverse events in patients with rheumatoid arthritis. A systematic review was performed in the electronic databases MEDLINE, Cochrane, Scopus, CRD, IPA, Lilacs and Scielo. Case reports addressing interruption of treatment due to any adverse event related to abatacept (ABA), adalimumab (ADA), anakinra (ANA), certolizumab pegol (CER), etanercept (ETA), golimumab (GOL), infliximab (IFX), rituximab (RTX), secukinumab (SEC), tocilizumab (TCZ), tofacitinib (TOF) or ustekinumab (UST) in rheumatoid arthritis patients were evaluated. Baseline data, patient profile, previous and current treatments, cause of discontinuation and information on reintroduction of treatment were extracted from the case reports. One hundred and fifty-four studies (154 patients) reported 162 discontinuations of rheumatoid arthritis treatment due to adverse events $(\mathrm{ETA}=57 ; \mathrm{IFX}=46 ; \mathrm{ADA}=32 ; \mathrm{TCZ}=13$; $\mathrm{RTX}=5 ; \mathrm{ANA}=3 ; \mathrm{GOL}=2 ; \mathrm{ABA}=2 ; \mathrm{TOF}=1 ; \mathrm{CER}=1 ; \mathrm{SEC}=0$ and $\mathrm{UST}=0)$. The mean age of patients was $56( \pm 12.1)$ years and $82 \%$ were female. Seventy-four adverse events were confirmed (related to used drug), and 138 were observed in patients using anti-TNF. The most common adverse events were infections (21\%), skin disease (15\%), autoimmune disease (13\%) and hematological disorders $(9 \%)$. Case reports are important in the detection of rare adverse events and should be considered in the choice of appropriate therapy for patients.
\end{abstract}

Keywords: Rheumatoid arthritis. Biological drugs/treatment interruption. Tofacitinib. Adverse events.

\section{INTRODUCTION}

Rheumatoid arthritis (RA) is a chronic and systemic autoimmune disease, and pathogenesis comprises environmental triggers (i.e. cigarette smoking) and multiple genetic factors (Mateen et al., 2016; Kim et al., 2017). With an estimated global prevalence of $1 \%$, RA affects primarily the small joints of the upper and lower extremities, and includes extra-articular manifestations, such as pulmonary disease and rheumatoid nodules (Kelmenson, Demoruelle, Deane, 2016; Smolen, Aletaha, McInnes, 2016; Lage-Hansen et al., 2017). RA causes substantial impairment in patients' quality of life, as the

\footnotetext{
*Correspondence: A. Wiens. Departamento de Farmácia, Universidade Federal do Paraná. Av. Prefeito Lothário Meissner 632 - Jardim Botânico CEP 80210-170 - Curitiba - Paraná - Brazil. Phone: 55-41-3360-4061 / Fax: 55-41-3360-4099. E-mail: astrid@ufpr.br
}

decline in physical function hinders the ability to perform daily activities, including the capacity to work. As RA induces a significant burden for patients and society, control of the disease in order to reduce or avoid further damage is crucial (Singh et al., 2016; Smolen, Aletaha, McInnes, 2016).

At first, non-steroidal anti-inflammatory drugs were used to reduce symptoms such as pain and joint swelling in patients diagnosed with RA. At present, EULAR (European League Against Rheumatism) guidelines recommend that patients initiate treatment with a diseasemodifying anti-rheumatic drug (DMARD) from the time of the diagnosis. In the absence of achievement of the treatment goal (i.e. inflammation reversal), the switch to a different DMARD or the addition of a biological or synthetic DMARD are strategies recommended by the guidelines (Murota et al., 2016; Zhou et al., 2016; Choy et al., 2017). The Food and Drug Administration 
(FDA, www.fda.gov) and European Medicines Agency (EMA, http://www.ema.europa.eu) currently approve biological DMARDs for RA treatment comprised of TNF inhibitors: adalimumab (ADA), etanercept (ETA), infliximab (IFX), certolizumab pegol (CER), golimumab (GOL); the anti-B-cell agent rituximab (RTX); the anti-T-cell co-stimulation agent abatacept (ABA); the interleukin-6 receptor inhibitor tocilizumab (TCZ); the interleukin-1 receptor antagonist anakinra (ANA); the interleukin 17A inhibitor secukinumab (SEC) and the interleukin 12 and 23 inhibitor ustekinumab (UST) (Scott et al., 2016; Smolen, Aletaha, McInnes, 2016; Tarp et al., 2017). Tofacitinib (TOF), despite being a synthetic DMARD, is currently incorporated in guidelines as a therapeutic choice after failure of other DMARDs (Smolen et al., 2017). This drug is a selective Janus kinase (JAK) inhibitor that preferentially inhibits JAKs 1 and 3 (Dhillon, 2017).

The recent use of these agents markedly improved RA treatment responses, reducing pain and stiffness and enhancing patient mobility (Pal et al., 2016). Despite several randomized controlled trials and meta-analyses addressing the use of biologic agents and TOF for RA treatment being published in recent years, evidence regarding discontinuation rates due to adverse events (AE) with these drugs is still weak. In addition, accurate information concerning $\mathrm{AE}$ and tolerability outcomes in clinical practice is difficult to gather (Abasolo et al., 2015). Hence, considering the severity and relevance of RA, and the need for evidence regarding tolerability and safety profiles of biological agents, the main goal of the present study was to systematically evaluate the reasons for treatment discontinuation and whether the relationship between the $\mathrm{AE}$ and the treatment in use was confirmed in patients with RA. This manuscript is part of a larger project that evaluates all types of studies concerning treatment interruption in RA patients. Case reports were selected as the primary source of information for this systematic review because they are useful in the recognition of singularities of therapies, and are usually the first studies that report new and rare AE, describing non-ordinary situations. Furthermore, they are suitable to generate hypotheses, and can be used to explore issues further (Hung et al., 2015).

\section{MATERIAL AND METHODS}

This study is part of a project that evaluates the reasons for discontinuation of biological treatments in RA in all types of studies (PROSPERO register number 42016033706).
A systematic review was performed in accordance with the Preferred Reporting Items for Systematic Reviews and Meta-Analyses (PRISMA) guidelines and Cochrane Collaboration recommendations. Electronic searches were conducted in the databases Medline (Pubmed), Lilacs, Scielo, Cochrane Library, Scopus, Center for Reviews and Dissemination and International Pharmaceutical Abstracts. The descriptors for treatment discontinuation/ interruption, biological agents (ABA, ADA, ANA, CER, ETA, GOL, IFX, RTX, TCZ, SEC and UST) and TOF, and rheumatoid arthritis were combined with Boolean operators (supplementary material). A manual search of the published articles was also performed. Studies in English, German, French, Italian, Spanish and Portuguese, published until December 2017, were included.

\section{Study selection}

\section{Inclusion criteria}

Case report studies reporting data on discontinuation due to $\mathrm{AE}$ of any of the biological drugs under evaluation or TOF at any dose/regimen in patients with RA at any stage were included, including those with any comorbidity.

\section{Exclusion criteria}

We excluded studies that did not mention interruption to treatment, or where the patient died without interrupting the treatment.

\section{Data screening}

Two independent reviewers screened titles and abstracts to identify irrelevant records. In a second stage, full-text articles were independently evaluated by these two researchers to select studies for inclusion; differences were resolved by consensus with a third reviewer.

\section{Data extraction}

Two reviewers independently extracted into Excel spreadsheets data from the selected studies on: (i) patient characteristics (age, gender, time of disease), (ii) clinical data (comorbidities, previous medication), (iii) therapies (biological drug or TOF dosage, administration route, concomitant drugs), (iv) AE (time of biological drug or TOF use until AE, first symptoms, reason for discontinuation, if the AE stopped after discontinuation and information about treatment re-introduction) and (v) information about the potential relationship of the AE with the drug. 


\section{Analyses}

All discontinuations due to AE related to the biological drug or TOF in RA patients were described. These AE were considered as adverse drugs reactions. When a confirmed relationship was reported between the reaction onset and the drug, they were described separately one by one in descriptive tables; whereas for AE possibly or probably related to the drug (no confirmed relationship between the $\mathrm{AE}$ and the biological agent), events were described according to the system affected (i.e. skin diseases, hematological disorders). Qualitative and quantitative comparisons were performed when possible to obtain a broader overview of all reported discontinuations.

\section{RESULTS}

This study is part of a project that aims to explore the discontinuation of biological treatment for RA reported in all types of studies. In the search for articles, all study types were searched simultaneously. In the current article, only the case reports are described.

In the first stage of the search for articles, 4,418 articles were found (Figure 1). Of these, 643 were duplicates and 2,766 were excluded based on their title and/or abstract. The other remaining 1,009 articles were fully read. Among these articles, 162 were the case reports included in this study. When interruptions due to an $\mathrm{AE}$ were reported for more than one drug in the same case report, multiple registers concerning each drug were created in order to separately describe each one of the AE, being called A, B and so on.

A total of 154 articles were found (supplementary material), describing 162 case reports that met the inclusion criteria. In descending order, the numbers of case reports found for each drug were: $\mathrm{ETA}=57$; IFX $=46$; $\mathrm{ADA}=32 ; \mathrm{TCZ}=13 ; \mathrm{RTX}=5 ; \mathrm{ANA}=3 ; \mathrm{GOL}=2 ; \mathrm{ABA}$ $=2 ; \mathrm{TOF}=1$ and $\mathrm{CER}=1$. No reports about interruption of ustekinumab or secukinumab in RA patients were found.

Of the 162 cases, $128(82 \%)$ occurred in female patients. The mean age of all patients was $56( \pm 12.1)$ years, and the patients' ages ranged from 24 to 80 years old. The disease duration ranged from 8 months to 48 years. Thirty-eight $(23 \%)$ case reports described the use of at least one previously known biological agent, and $76(47 \%)$ described the concomitant use of synthetic DMARD (Table I).

The time of treatment until the onset of the AE that led to drug interruption ranged from two days to seven years. There were 66 (41\%) confirmed AE (Table II), that is cases where the $\mathrm{AE}$ was certainly related to the use of the evaluated drug: 22 cases related to IFX therapy; 19 to ETA;

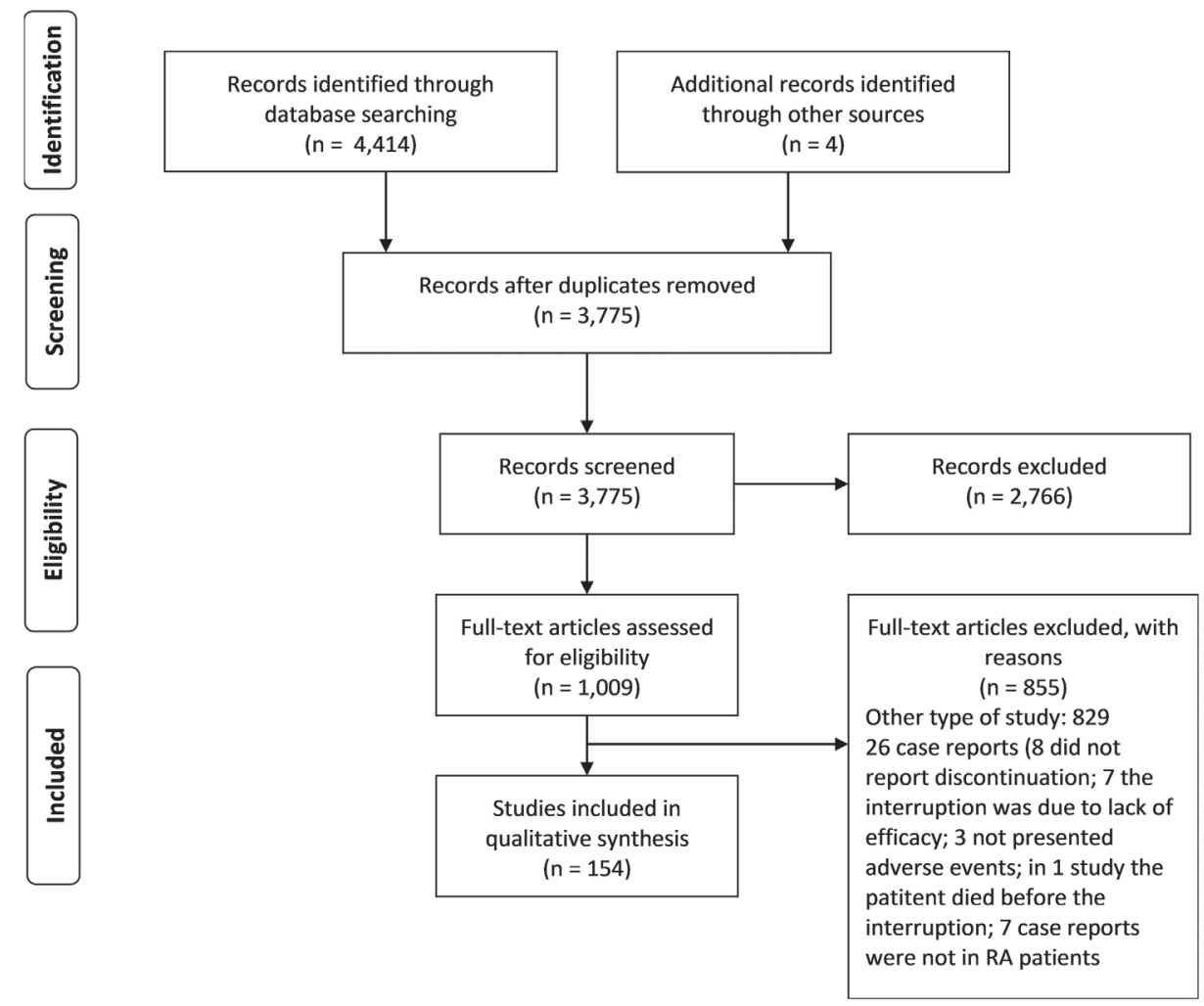

FIGURE 1 - Flowchart of study selection. 
16 to ADA; 6 to TCZ; 1 to ANA; 1 to GOL and 1 to RTX. The other AE were suspected or probably associated with the drug, but without confirmation. Regarding the reported comorbidities, the most frequent was hypertension $(12 \%$ - 19 patients), followed by chronic $\mathrm{C}$ hepatitis, thyroiditis and Sjörgen syndrome (3\% - 5 patients each).

One hundred and thirty-eight (85\%) events happened in patients using anti-TNF therapy (ADA, CER, ETA, GOL or IFX). Of these patients, $12(9 \%)$ restarted the same drug after resolution of the AE, and another 29 (21\%) switched to another drug of the same class (anti-TNF). Of those who returned to the same drug, in nine $(75 \%)$ patients the AE occurred again and the medication had to be stopped once more. Of those who switched to another anti-TNF, 11 (38\%) experienced an AE that led to further discontinuation of treatment.

Of the 13 patients who discontinued treatment while using anti-TNF and started a drug from another class, only one study ( $8 \%$ ) described a further discontinuation of treatment. However, it is important to mention that some serious AE may have occurred after the articles were published and, therefore, may not have been documented.

Considering the $162 \mathrm{AE}, 33(21 \%)$ were related to serious infections, $25(15 \%)$ to skin diseases, 21 (13\%) to autoimmune reactions, $14(9 \%)$ to hematological disorders, $11(7 \%)$ to allergies and $8(5 \%)$ to hepatitis, while neoplasias, infusion reactions and reactions in the cardiovascular system represented 6 (4\%) AE each (Figure 2).

Of the 95 remaining AE that were considered suspect or possible, $20(21 \%)$ were related to serious infections, $14(15 \%)$ to skin diseases and $11(12 \%)$ to autoimmune diseases, whereas allergies, hepatitis and hematological disorders occurred in six (6\%) patients each.

Eight $\mathrm{AE}$ that led to treatment discontinuation occurred in patients who had already had a biological drug suspension due to an AE. These cases are described below. One patient presented three interruptions due to allergic reactions (using ADA, ETA and ANA) (Desai et al., 2009). Another patient presented labial angioedema and tongue swelling during treatment with ADA. She started to use ETA, and after three months experienced epistaxis and bleeding in the mouth, leading to treatment discontinuation. She returned to ADA, and after six months presented erythema at the injection sites. The treatment was stopped and she started RIT, without report of any more AE (Abadoglu et al., 2011). One woman experienced hypertension and headaches that resulted in treatment discontinuation. She started treatment with IFX, and after the third dose a complete heart block occurred. The patient stopped IFX (Sote, Green, Maddison, 2008). In other case report, a woman experienced an infusion reaction after 40 weeks of IFX. She stopped IFX and started ETA. After 19 months, she developed cellulitis in the arm and discontinued ETA (Deniz et al., 2012). A woman developed severe angioedema after the second IFX administration and stopped treatment. She started ADA, and after two months presented a psoriatic-like skin reaction. She discontinued ADA and started RIT with methotrexate (Mourao et al., 2010). A patient presented an infusion reaction after IFX administration. Treatment was interrupted and restarted after four weeks using concomitant premedication. This patient interrupted the treatment again due to scleredema (Ranganathan, 2005).

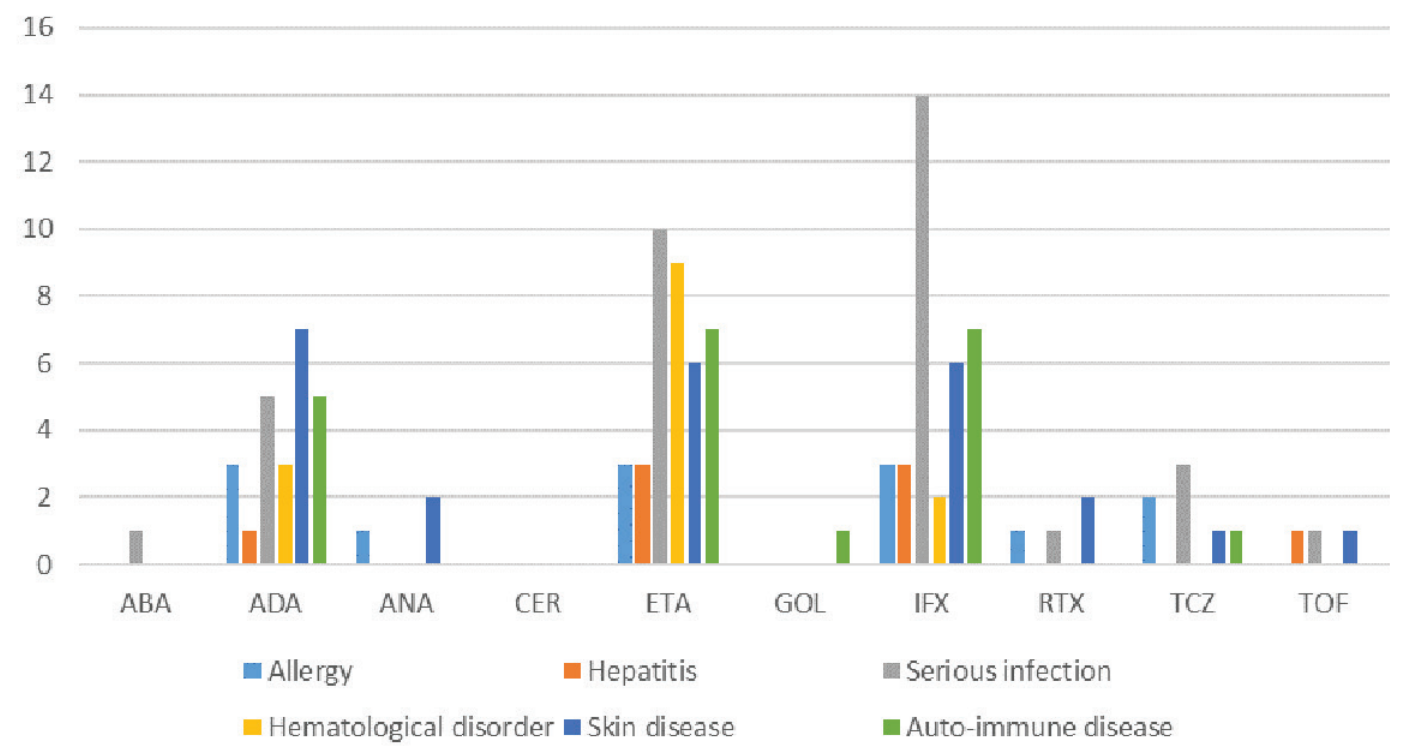

FIGURE 2 - Most common adverse events according to the type of rheumatoid arthritis treatment. 
TABLE I - Characteristics of included case reports

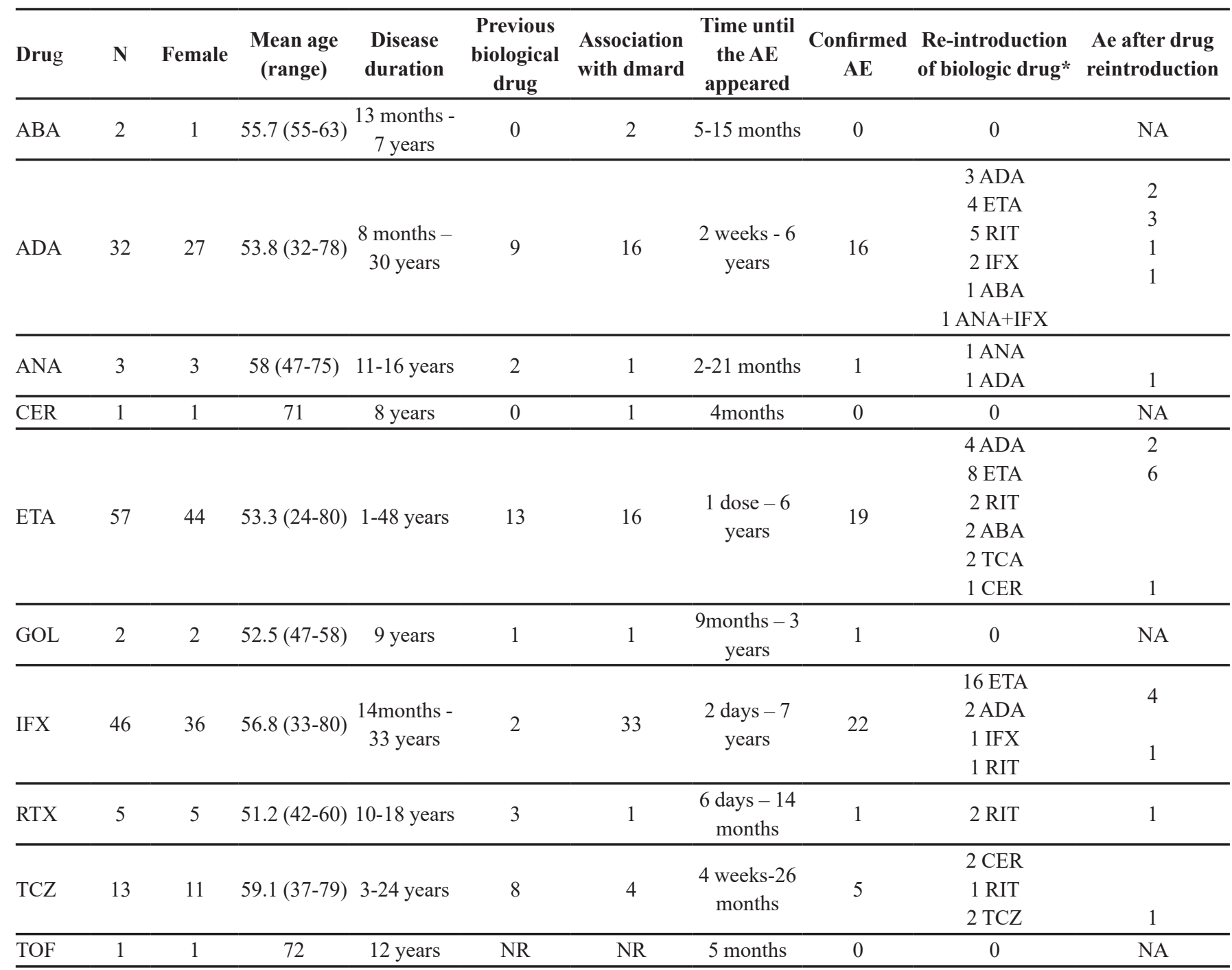

$\mathrm{N}=$ number of patients; $\mathrm{AE}=$ adverse event; $\mathrm{ABA}=$ abatacept; $\mathrm{ADA}=$ adalimumab; $\mathrm{ANA}=$ anakinra; $\mathrm{CER}=$ certolizumab; $\mathrm{ETA}=\mathrm{etanercept}$; $\mathrm{GOL}=$ golimumab; IFX=infliximab; RTX=rituximab; TCZ=tocilizumab; $\mathrm{NA}=$ not applicable; $\mathrm{NR}=$ not related. * related in the article

\section{DISCUSSION}

This is a descriptive study describing only AE with biologicals and TOF that led to discontinuation of treatment in patients with rheumatoid arthritis. Only case reports were selected for this systematic review. Case control studies are important because they usually describe rare situations found in clinical practice, at any moment, and not just tied to the conduction period of a study. Thus, they are of paramount importance to detect rare AE. Furthermore, case reports can describe a situation experienced by a patient with a specific condition (that might not be eligible for other types of studies), and allows exploration of this data, presenting relevant information for exceptional circumstances.
An important factor to observe when analyzing the number of reports on $\mathrm{AE}$ is the time that each drug is on the market. While ABA, ADA, ANA, ETA, IFX and RTX have been marketed for more than 10 years, CER, GOL and TCZ are more recent and have been approved by the FDA for eight, seven and six years, respectively. Therefore, some medications have been used for less time and in less quantity; logically, there are fewer studies and reports in the literature on their use.

In the included case reports, we did not find data on previous treatments for all patients before starting the biological drug. However, according to international recommendations (EULAR, ACR - American College of Rheumatology, and NICE - The National Institute for Health and Care Excellence), patients should start 
TABLE II - Description of confirmed adverse event

\begin{tabular}{|c|c|c|c|c|c|}
\hline Drug & Age & $\begin{array}{l}\text { Previously biological } \\
\text { drug }\end{array}$ & Time of treatment & Adverse event & $\begin{array}{c}\text { AE disappeared } \\
\text { with suspension of } \\
\text { biological drug }\end{array}$ \\
\hline \multirow{16}{*}{ ADA } & 32 & \multirow{9}{*}{ ADA and ETA } & 2 weeks & labial angioedema and tongue swelling & $\mathrm{Y}$ \\
\hline & 32 & & 6 months & $\begin{array}{l}\text { erythema at the injection sites lasting more } \\
\text { than } 24 \text { hours }\end{array}$ & Y \\
\hline & 66 & & 1 year & Alopecia universalis & Y \\
\hline & 63 & & 12 weeks & Severe cutaneous reaction & Y \\
\hline & 51 & & 4 months & pustular drug eruption & Y \\
\hline & 55 & & 10 weeks & Neutropenia & Y \\
\hline & 55 & & 9 months & Tuberculosis & $\mathrm{Y}$ \\
\hline & 75 & & 4 months & Inrection with nocardia & Y \\
\hline & 51 & & 6 months & Generalized pustulosis & $\mathrm{N}$ \\
\hline & 33 & INF & 2 months & psoriatic like skin reaction & Y \\
\hline & 60 & INF & 13 weeks & Urticaria and angiedema-like skin reactions & Y \\
\hline & 35 & ETA & 2 months & Autoimmune hepatitis & Y \\
\hline & 57 & \multirow{4}{*}{ INF and ETA } & 7 weeks & Injection site reaction & $\mathrm{Y}$ \\
\hline & 64 & & 7 months & interstitial pneumonia & Y \\
\hline & 71 & & 6 years & Tuberculosis of the tongue & Y \\
\hline & 52 & & 4 months & lichenoid drug eruption & $\mathrm{Y}$ \\
\hline ANA & 52 & & 21 months & Interstitial granulomatous drug reaction & $\mathrm{Y}$ \\
\hline \multirow{19}{*}{ ETA } & 32 & ADA & 3 months & epistaxis and bleeding in the mouth & $\mathrm{Y}$ \\
\hline & 50 & $\mathrm{INF}$ & 2 years & extensive pulmonary nodulosis & Y \\
\hline & 44 & $\mathrm{ADA}$ & 2 weeks & injection site reactions & $\mathrm{Y}$ \\
\hline & 70 & & 8 months & Lichen striatus & Y \\
\hline & 58 & & 2 weeks & leukocytoclastic vasculitis & Y \\
\hline & 61 & & 2 months & perforating folliculitis & Y \\
\hline & 66 & & 2 years & Demyelinating disorder & Y \\
\hline & 56 & & 1 months & $\begin{array}{l}\text { Diffuse Alveolar Hemorrhage and Acute } \\
\text { Respiratory Distress Syndrome }\end{array}$ & $*$ \\
\hline & 70 & & 8 weeks & Dermatitis & $\mathrm{Y}$ \\
\hline & 52 & & 40 weeks & cold agglutinin disease & Y \\
\hline & 66 & & 2 years & Oligoarticular Septic Arthritis & Y \\
\hline & 64 & $\mathrm{ADA}$ & 1 weeks & Lymphopenia & Y \\
\hline & 55 & & 3 months & Delayed multiple injection site reaction & Y \\
\hline & 33 & $\mathrm{ADA}$ & 6 months & Tuberculose & Y \\
\hline & 30 & & 2 months & Psoriasis & Y \\
\hline & 80 & INF & 1 months & subacute prurigo with eosinophilia & $\mathrm{Y}$ \\
\hline & 37 & & 20 weeks & etanercept-induced liver dysfunction & Y \\
\hline & 64 & $\mathrm{ADA}$ & 3 weeks & Lymphopenia & Y \\
\hline & 33 & $\mathrm{ADA}$ & 1 months & Allergic reaction & $\mathrm{Y}$ \\
\hline GOL & 47 & $\mathrm{ADA}$ & 9 months & Subacute Systemic Lupus Erythematous & $\mathrm{Y}$ \\
\hline \multirow{4}{*}{ IFX } & 49 & \multirow{4}{*}{ ADA and ETA } & 4 doses & Leprosy & $\mathrm{Y}$ \\
\hline & 78 & & 6 weeks & complete heart block & Y \\
\hline & 62 & & 7 years & Lymphoma & $\mathrm{Y}$ \\
\hline & 53 & & 9 doses & Leishmaniose visceral & $\mathrm{Y}$ \\
\hline
\end{tabular}


TABLE II - Description of confirmed adverse event (cont.)

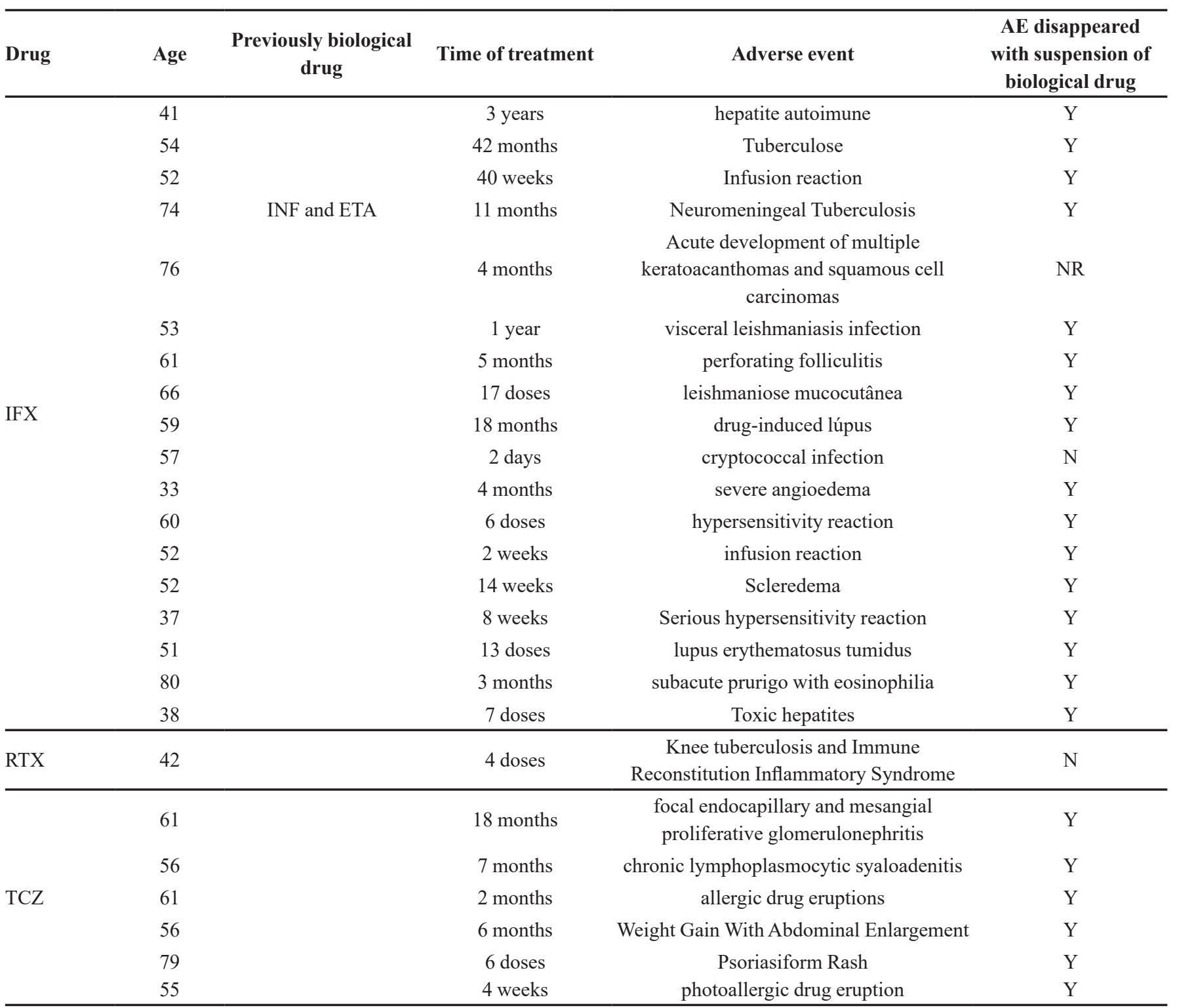

ABA=abatacept; $\mathrm{ADA}=$ adalimumab; ANA=anakinra; $\mathrm{CER}=$ certolizumab; ETA=etanercept; $\mathrm{GOL}=$ golimumab; IFX=infliximab; RTX=rituximab; $\mathrm{TCZ}=$ tocilizumab; $\mathrm{NR}=$ not related; * Patient died 2 weeks after interruption.

treatment with conventional DMARD before using a biological drug (Singh et al., 2012; NICE, 2013; Smolen et al., 2014). Most guidelines recommend biological exchange in case of discontinuation of a biological drug or TOF due to AE, but it is still not defined whether this exchange should be between the same class or not. In the case reports included in our study, we could not evaluate the recurrence of the AE when using drugs of the same class, as many of the reports were published soon after the resolution of the $\mathrm{AE}$, without presenting the continuity of the treatment. An observational study that evaluated the exchange between anti-TNF (only ADA, ETA and IFX) in
72 patients described that switching from one anti-TNF to another could be beneficial for patients treated first with a molecule with satisfactory efficacy, especially if that firstline biological agent was a monoclonal antibody (ADA or IFX). On the other hand, if the patient was in primary failure and received ETA as first-line therapy, it would seem better to propose another class of biological therapy (Lequerre et al., 2015).

The most commonly reported AE leading to treatment discontinuation presented on the case reports was serious infections. In a meta-analysis (Gartlehner et al., 2006) that evaluated the efficacy and safety of agents 
(ABA, ADA, ANA, ETA, IFX and RTX) in RA patients who had previously failed with DMARD treatment, the incidence of serious infections was markedly higher in the biological agents group when compared to the placebo group. In that study, tuberculosis was the most common infection reported. Their systematic review included only articles published in English, and observational studies were elected to evaluate AE. Infusion reactions were the most reported AE for IFX, RTX and ABA, while injection site reactions, such as pruritus, rash, pain and erythema, were the most common for ETA, ADA and ANA. In our systematic review, infusion reactions were found in case reports of ADA (2), ETA (1) and IFX (3).

A Cochrane systematic review was published in 2011 evaluating the cases of serious infections, tuberculosis reactivation, lymphoma and congestive heart failure caused by biological agents reported in controlled trials and extension studies. The authors concluded that the number of $\mathrm{AE}$ and discontinuation due to $\mathrm{AE}$ is higher in the immunobiologicals compared to placebo, but does not differ among the drugs (Singh et al., 2011). The first meta-analysis evaluating the rate of discontinuation of biological agents for rheumatoid arthritis (Souto, Maneiro, Gomez-Reino, 2016) used world drug registries and healthcare databases. Regarding TNF inhibitors, their comprehensive systematic review showed a higher rate of discontinuation due to AE for ADA and IFX when compared to ETA for all the evaluated periods (six months and one, two, three and four years). TCZ also presented more cases of discontinuation due to AE than ETA, and similar rates when compared to ADA and IFX. In our study, most of the case reports on drug interruption were related to ETA, followed by IFX and ADA. Due to the nature of the primary source of information used in our present systematic review, which may carry a publication bias, it is not possible to infer that ETA is more associated to AE leading to drug interruption. However, it is possible to notice that drug discontinuation with ETA was more reported in case reports when compared to the other addressed biological agents, a fact that should be better investigated.

In the first mixed treatment comparison (MTC) meta-analysis addressing outcome tolerability in terms of discontinuation due to AE of ABA versus TNF inhibitors (Hochberg et al., 2013), the authors identified 15 randomized, placebo-controlled trials through systematic review. Regarding tolerability outcomes for both periods evaluated (6 and 12 months), a higher probability of drug discontinuation due to $\mathrm{AE}$ was found for TNF inhibitors compared to $\mathrm{ABA}$, indicating that the latter may have a better tolerability profile. The findings from our study corroborate the results obtained by this MTC (Hochberg et al., 2013), as the majority of case reports on drug interruption due to AE were related to the TNF inhibitors ETA (57), IFX (46) and ADA (31), while only two cases addressing ABA were retrieved.

Among skin diseases, psoriasis, dermatitis and other serious skin reactions have been reported. Clinically important dermatological conditions in RA patients treated with anti-TNF were investigated by Flendrie et al. (2005). The cohort study evaluated 911 patients using ADA, ETA or IFX. Skin infections, eczema and drug-related eruptions were the most common events $(33,20$ and 15 patients, respectively), whereas psoriasis was found in three patients. In our study, 25 skin disorders were reported, including psoriasis (seven case reports). TNF-alfa induced psoriasis was described previously in a systematic review, where the cessation of anti-TNF therapy may have resulted in resolution of half of the cases (Brown et al., 2017).

Autoimmune reactions constituted the third most reported $\mathrm{AE}$ leading to biological discontinuation in case reports. Considering that the targets of the biological agents (cytokines and dysregulated cells of the immune system) are also crucial constituents of immune homeostasis, it is not astonishing that the use of these agents promoted AE in this system (Her, Kavanaugh, 2016). The association between biological agents and the development of new autoimmune diseases has already been described in the literature. Among the biological agents, the class of TNF inhibitors has been pointed out as the foremost related to development of systemic autoimmune reactions. Previous studies have indicated lupus as the most frequently induced disease, followed by vasculitis and sarcoidosis (Perez-Alvarez et al., 2013; Her, Kavanaugh, 2016). The development of lupus was described in two case reports as confirmed AE leading to drug discontinuation in our systematic review. Both reports were related to TNF inhibitors (GOL and IFX). Vasculitis was reported in one case with ETA and no report of sarcoidosis was retrieved. TNF inhibitors were also found to be associated with the appearance of psoriatic skin lesions, which has been reported by several observational studies in the last years (Ciccarelli et al., 2016). In our study, development of psoriatic skin lesions was described in three case reports as confirmed AE leading to biological discontinuation. Two of the three reports were on TNF inhibitors (ADA and ETA) and one was on TCZ. Finally, one case of autoimmune hepatitis was described with ADA. The development of drug-induced autoimmune hepatitis was reported in a few cases in the literature with the use of TNF inhibitors. Nevertheless, the appearance of the disease during the treatment course with a biological agent should 
be carefully evaluated, since it may not necessarily reflect a de novo disease onset (Efe, 2013). Despite the severity of some autoimmune-induced diseases, the suspension of the biological agent usually improves the symptoms (Rubbert-Roth, 2012), as observed in all autoimmuneinduced reactions reported in the retrieved cases.

The major limitation of the present study is the paucity of evidence obtained from case reports, which may carry a publication bias. Moreover, many case reports do not present patient histories, previous treatments or dose of the drug. In addition, many are written shortly after treatment discontinuation, not describing whether treatment was re-introduced. Nevertheless, in order to minimize the risk of bias, the comprehensive search performed in this study attempted to retrieve all published case reports on drug interruption with biologicals for RA treatment, in order to drawn a broader overview of the causes of drug discontinuation.

Despite the study limitations addressed above, our findings are in agreement with the results from other studies evaluating the safety and tolerability of biological agents for RA treatment.

The objective of the present study was not to generate new evidence, as it was not possible to perform any quantitative synthesis of the results. Our goal was to search for and describe rare $\mathrm{AE}$ and uncommon situations that may appear in patients using biological drugs or TOF for RA treatment during the last several years, and gather all this information in a single source of information.

\section{CONFLICTS OF INTEREST}

\section{Disclosures - none.}

This work was supported by Fellow of the Brazilian National Council of Scientific Research-CNPq (grant Universal 14/2014 - 442095/2014-7)

\section{REFERENCES}

Abadoglu O, Epozturk K, Atayik E, Kaptanoglu E. Successful rapid rituximab desensitization for hypersensitivity reactions to monoclonal antibodies in a patient with rheumatoid arthritis: a remarkable option. J Investig Allergol Clin Immunol. 2011;21(4):319-321.

Abasolo L, Leon L, Rodriguez-Rodriguez L, Tobias A, Rosales $\mathrm{Z}$, Maria Leal J, et al. Safety of disease-modifying antirheumatic drugs and biologic agents for rheumatoid arthritis patients in real-life conditions. Semin Arthritis Rheum. 2015;44(5):506513.
Brown G, Wang E, Leon A, Huynh M, Wehner M, Matro R, et al. Tumor necrosis factor-alpha inhibitor-induced psoriasis: Systematic review of clinical features, histopathological findings, and management experience. J Am Acad Dermatol. 2017;76(2):334-341.

Choy E, Aletaha D, Behrens F, Finckh A, Gomez-Reino J, Gottenberg JE, et al. Monotherapy with biologic diseasemodifying anti-rheumatic drugs in rheumatoid arthritis. Rheumatology (Oxford). 2017;56(5):689-697.

Ciccarelli F, De Martinis M, Sirufo MM, Ginaldi L. Psoriasis Induced by Anti-Tumor Necrosis Factor Alpha Agents: A Comprehensive Review of the Literature. Acta Dermatovenerol Croat. 2016;24(3):169-174.

Deniz D, Ebru U, Ajda B, Gulsum TM, Semih T, Aytul C. A case of cellulitis causing tissue defect during etanercept therapy. Rheumatol Int. 2012;32(1):241-244.

Desai D, Goldbach-Mansky R, Milner JD, Rabin RL, Hull K, Pucino F, et al. Anaphylactic reaction to anakinra in a rheumatoid arthritis patient intolerant to multiple nonbiologic and biologic disease-modifying antirheumatic drugs. Ann Pharmacother. 2009;43(5):967-972.

Dhillon S. Tofacitinib: A Review in rheumatoid arthritis. Drugs. 2017;77(18):1987-2001.

Efe C. Drug induced autoimmune hepatitis and TNF-alpha blocking agents: is there a real relationship? Autoimmun Rev. 2013;12(3):337-339.

Flendrie M, Vissers WH, Creemers MC, de Jong EM, van de Kerkhof PC, van Riel PL. Dermatological conditions during TNF-alpha-blocking therapy in patients with rheumatoid arthritis: a prospective study. Arthritis Res Ther. 2005;7(3):R666676.

Gartlehner G, Hansen RA, Jonas BL, Thieda P, Lohr KN. The comparative efficacy and safety of biologics for the treatment of rheumatoid arthritis: a systematic review and metaanalysis. J Rheumatol. 2006;33(12):2398-2408.

Her M, Kavanaugh A. Alterations in immune function with biologic therapies for autoimmune disease. J Allergy Clin Immunol. 2016;137(1):19-27. 
Hochberg MC, Berry S, Broglio K, Rosenblatt L, Nadkarni A, Trivedi D, et al. Mixed treatment comparison of efficacy and tolerability of biologic agents in patients with rheumatoid arthritis. Curr Med Res Opin. 2013;29(10):1213-1222.

Hung BT, Long NP, Hung le P, Luan NT, Anh NH, Nghi TD, et al. Research trends in evidence-based medicine: a joinpoint regression analysis of more than 50 years of publication data. PLoS One. 2015;10(4):e0121054.

Kelmenson LB, Demoruelle MK, Deane KD. The Complex Role of the Lung in the Pathogenesis and Clinical Outcomes of Rheumatoid Arthritis. Curr Rheumatol Rep. 2016;18(11):69.

Kim K, Bang SY, Lee HS, Bae SC. Update on the genetic architecture of rheumatoid arthritis. Nat Rev Rheumatol. 2017;13(1):13-24.

Lage-Hansen PR, Lindegaard H, Chrysidis S, Terslev L. The role of ultrasound in diagnosing rheumatoid arthritis, what do we know? An updated review. Rheumatol Int. 2017;37(2):179-187.

Lequerre T, Farran E, Menard JF, Kozyreff-Meurice M, Vandhuick T, Tharasse C, et al. Switching from an anti-TNF monoclonal antibody to soluble TNF-receptor yields better results than vice versa: An observational retrospective study of 72 rheumatoid arthritis switchers. Joint Bone Spine. 2015;82(5):330-337.

Mateen S, Moin S, Zafar A, Khan AQ. Redox signaling in rheumatoid arthritis and the preventive role of polyphenols. Clin Chim Acta. 2016;463:4-10.

Mourao AF, Canhao H, Sousa E, Cascao R, da Costa JB, de Almeida LS, et al. From a neutrophilic synovial tissue infiltrate to a challenging case of rheumatoid arthritis. Acta Reumatol Port. 2010;35(2):228-231.

Murota A, Kaneko Y, Yamaoka K, Takeuchi T. Safety of biologic agents in elderly patients with rheumatoid arthritis. J Rheumatol. 2016;43(11):1984-1988.

NICE. National Institute for Health and Care Excellence. NICE clinical guideline 79 - Rheumatoid arthritis - The management of rheumatoid arthritis in adults. 2013.

Pal S, Veeravalli SC, Das SK, Shobha V, Uppuluri RR, Dharmanand BG, et al. Efficacy and safety of golimumab in Indian patients with rheumatoid arthritis: Subgroup data from GO-MORE study. Int J Rheum Dis. 2016;19(11):1083-1092.
Perez-Alvarez R, Perez-de-Lis M, Ramos-Casals M, group Bs. Biologics-induced autoimmune diseases. Curr Opin Rheumatol. 2013;25(1):56-64.

Ranganathan P. Infliximab-induced scleredema in a patient with rheumatoid arthritis. J Clin Rheumatol. 2005;11(6):319-322.

Rubbert-Roth A. Assessing the safety of biologic agents in patients with rheumatoid arthritis. Rheumatology (Oxford). 2012;51(Suppl 5):38-47.

Scott IC, Ibrahim F, Simpson G, Kowalczyk A, White-Alao B, Hassell A, et al. A randomised trial evaluating anakinra in early active rheumatoid arthritis. Clin Exp Rheumatol. 2016;34(1):8893.

Singh JA, Furst DE, Bharat A, Curtis JR, Kavanaugh AF, Kremer JM, et al. 2012 update of the 2008 American College of Rheumatology recommendations for the use of diseasemodifying antirheumatic drugs and biologic agents in the treatment of rheumatoid arthritis. Arthritis Care Res (Hoboken). 2012;64(5):625-639.

Singh JA, Saag KG, Bridges SL, Jr., Akl EA, Bannuru RR, Sullivan MC, et al. 2015 American College of Rheumatology Guideline for the Treatment of Rheumatoid Arthritis. Arthritis Care Res (Hoboken). 2016;68(1):1-25.

Singh JA, Wells GA, Christensen R, Tanjong Ghogomu E, Maxwell L, Macdonald JK, et al. Adverse effects of biologics: a network meta-analysis and Cochrane overview. Cochrane Database Syst Rev. 2011;(2):CD008794.

Smolen JS, Aletaha D, McInnes IB. Rheumatoid arthritis. Lancet. 2016;388(10055):2023-2038.

Smolen JS, Landewe R, Bijlsma J, Burmester G, Chatzidionysiou $\mathrm{K}$, Dougados M, et al. EULAR recommendations for the management of rheumatoid arthritis with synthetic and biological disease-modifying antirheumatic drugs: 2016 update. Ann Rheum Dis. 2017;76(6):960-977.

Smolen JS, Landewe R, Breedveld FC, Buch M, Burmester $\mathrm{G}$, Dougados M, et al. EULAR recommendations for the management of rheumatoid arthritis with synthetic and biological disease-modifying antirheumatic drugs: 2013 update. Ann Rheum Dis. 2014;73(3):492-509.

Sote Y, Green S, Maddison P. Complete heart block after infliximab therapy. Rheumatology (Oxford). 2008;47(2):227228. 
Souto A, Maneiro JR, Gomez-Reino JJ. Rate of discontinuation and drug survival of biologic therapies in rheumatoid arthritis: a systematic review and meta-analysis of drug registries and health care databases. Rheumatology (Oxford). 2016;55(3):523534.

Tarp S, Furst DE, Dossing A, Ostergaard M, Lorenzen T, Hansen MS, et al. Defining the optimal biological monotherapy in rheumatoid arthritis: A systematic review and meta-analysis of randomised trials. Semin Arthritis Rheum. 2017;46(6):699-708.
Zhou RP, Wu XS, Xie YY, Dai BB, Hu W, Ge JF, et al. Functions of interleukin-34 and its emerging association with rheumatoid arthritis. Immunology. 2016;149(4):362-373.

Received for publication on $31^{\text {st }}$ July 2017 Accepted for publication on $16^{\text {th }}$ April 2018 